\title{
Correction to: Review of Cognitive Characteristics of Autism Spectrum Disorder Using Performance on Six Subtests on Four Versions of the Wechsler Intelligence Scale for Children
}

\author{
Mizuho Takayanagi ${ }^{1}$ (D) $\cdot$ Yoko Kawasaki $^{2} \cdot$ Mieko Shinomiya $^{2} \cdot$ Hoshino Hiroshi $^{3} \cdot$ Satoshi Okada $^{4} \cdot$ Tamiko Ino $^{2} \cdot$ \\ Kazuko Sakai ${ }^{2} \cdot$ Kimiko Murakami $^{2} \cdot$ Rie Ishida $^{2} \cdot$ Kaoru Mizuno $^{2} \cdot$ Shin-Ichi Niwa ${ }^{3}$
}

Published online: 23 April 2021

(C) The Author(S) 2021

\section{Correction to: Journal of Autism and Developmental Disorders https://doi.org/10.1007/s10803-021-04932-x}

The article Review of Cognitive Characteristics of Autism Spectrum Disorder Using Performance on Six Subtests on Four Versions of the Wechsler Intelligence Scale for Children, written by Mizuho Takayanagi, was originally published electronically on the publisher's internet portal on 7 March 2021 without open access. With the author(s)' decision to opt for Open Choice the copyright of the article changed on 5 April 2021 to () The Author(s) 2021 and the article is forthwith distributed under a Creative Commons Attribution.

Open Access This article is licensed under a Creative Commons Attribution 4.0 International License, which permits use, sharing, adaptation, distribution and reproduction in any medium or format, as long as you give appropriate credit to the original author(s) and the source, provide a link to the Creative Commons licence, and indicate if changes were made. The images or other third party material in this article are included in the article's Creative Commons licence, unless indicated otherwise in a credit line to the material. If

The original article can be found online at https://doi.org/10.1007/ s10803-021-04932-x.

Mizuho Takayanagi

arisawabashimi@gmail.com

1 Department of Child and Adolescent Psychiatry,

Arisawabashi Hospital, 5 Fuchu-machi Haneshin, Toyama,

Toyama 9392704, Japan

2 Musashino Child Development Clinic, Tokyo, Japan

3 Fukushima Medical University, Fukushima, Japan

4 Hokkaido University, Hokkaido, Japan material is not included in the article's Creative Commons licence and your intended use is not permitted by statutory regulation or exceeds the permitted use, you will need to obtain permission directly from the copyright holder. To view a copy of this licence, visit http://creativecommons. org/licenses/by/4.0/.

Publisher's Note Springer Nature remains neutral with regard to jurisdictional claims in published maps and institutional affiliations. 